\title{
Biliary Atresia Splenic Malformation Syndrome: A Single Center Experience
}

Onder Ozden ${ }^{1}$,[MD]

ORCID: 0000-0001-5683-204X

Seref Selcuk Kilic ${ }^{1},[\mathrm{MD}]$

ORCID: 0000-0002-1427-0285

Murat Alkan ${ }^{1},[\mathrm{MD}]$

ORCID: 0000-0001-5558-9404

Gokhan Tumgor ${ }^{2}$,[MD]

ORCID: 0000-0002-3919-002X

Recep Tuncer ${ }^{1}$,[MD]

ORCID: 0000-0003-4670-8461

1, ${ }^{*}$ Cukurova University Department of Pediatric Surgery, Adana, Turkey

${ }^{2}$ Cukurova University Department of Pediatric Gastroenterology,

* Corresponding Author: Dr. Önder Özden

Cukurova University, Department of Pediatric Surgery

Address: Çukurova Üniversitesi Balcalı Hastanesi Çocuk Cerrahisi Anabilim Dalı 01330 Sarıçam/Adana, Turkey Email: onder24@hotmail.com

Tel: +905373104769 re) ABSTRACT Cen

Objective: Biliary atresia splenic malformation (BASM) syndrome which is a subgroup of BA is associated with situs inversus, intestinal malrotation, polysplenia, preduodenal portal vein, interrupted vena cava, congenital portocaval shunts and cardiac anomalies. We aimed to report our experiences in BASM management and association of CMV infection.

Materials and Methods: The data were collected retrospectively from medical records of patients treated in Cukurova University between 2005-2017. Sex, age, liver function tests, serological test results, BA types, surgical findings, and mortality were noted.

Results: Fifty-nine BA patients were diagnosed in the study period. Seven of them were classified as BASM. The median age was 60 days (45-90 days) with a female/male ratio of $3 / 4$. The main complaint of all patients was jaundice. The jaundice of 6 patients began since birth and one began at 20 daysage. Median total/direct blood bilirubin levels were 9.6/5.4 mg/dL. Median values of liver function tests; ALT, AST, and GGT were 77 IU/L, $201 \mathrm{IU} / \mathrm{L}$ and $607 \mathrm{IU} / \mathrm{L}$ respectively. Five of the patients showed positive results for anti-CMV Ig M. All patients had positive anti-CMV Ig G. One patient had type $2 \mathrm{BA}$ and all others had type $3 \mathrm{BA}$. Associated anomalies were polysplenia $(n=4)$, asplenia $(n=1)$, preduodenal portal vein $(n=5)$, midgut malrotation $(n=7)$, inferior vena cava interruption $(n=1)$ and hepatic artery originating from superior mesenteric artery (SMA) $(n=1)$. Patients had Ladd procedure $(n=7)$, duodenoduodenostomy $(n=5)$ along with Kasai portoenterostomy. The median follow-up time was 4 years (1-5 years). All patients are alive and one had liver transplantation.

Conclusion: Patients with BASM represent a distinct subgroup of BA which may have additional gastrointestinal anomalies such as midgut malrotation and preduodenal portal vein. Thus additional procedures such as duodenoduodenostomy and Ladd procedure may be added to Kasai portoenterostomy. Further research is recommended for CMV infections role in BASM pathogenesis.

Received: 29 April 2019, Accepted: 21 November 2019,

Published online: 31 December 2019

\section{INTRODUCTION}

Biliary atresia (BA) is a rare, progressive, inflammatory disease of the bile ducts. It is a destructive cholangiopathy that eventually leads to liver cirrhosis. The etiology of $\mathrm{BA}$ is still unknown and its incidence varies between $1 / 9000$ and $1 / 15000$, depending on the country [1]. Biliary atresia splenic malformation (BASM) syndrome which is a subgroup of BA is associated with congenital abnormalities, including situs inversus, intestinal malrotation, polysplenia, preduodenal portal vein, interrupted vena cava, congenital portocaval shunts, and cardiac anomalies. The incidence of BASM also varies according to the country. The incidence of BASM cases among all cases of BA is 5\% in China, 10\% in England, 13\% in 
Canada and 5\% in Japan [2-5].

The Japanese Association of Pediatric Surgeons classifies BA into 3 types. There is common bile duct atresia with patent proximal bile ducts in type $1 \mathrm{BA}$. In type 2 BA, the main hepatic, cystic, and common bile ducts are atretic with patent right and left hepatic ducts. Finally, in type $3 \mathrm{BA}$, the intrahepatic bile ducts are also atretic. Another classification scheme according to Davenport, divides BA into 4 clinical groups. These are syndromic BA, cystic BA, CMV-associated BA, and isolated BA. In this classification system, BASM is a subgroup of syndromic BA [6].

There is a well-established association between BA and cytomegalovirus (CMV) infection, and such cases are termed as CMV associated BA.

In this study, we aimed to present our data with special emphasis on additional interventions such as duodenoduodenostomy in cases with preduodenal portal vein and Ladd procedure in midgut malrotation besides association of BASM and CMV infection.

\section{MATERIALS and METHODS}

Medical records of patients who were diagnosed as BA between 2005 and 2017 were evaluated. Patients with $B A$ were included in the study if they had one of the following anomalies: asplenia, polysplenia, heterotaxy syndrome, inferior vena cava portal vein anomalies, intestinal rotational anomalies, and cardiac anomalies. Patients with an association of BA and other common congenital abnormalities (undescended testis, hypospadias) were excluded. The patient's sex, age, liver function tests, serological tests of Toxoplasma infection, syphilis, varicella-zoster, parvovirus B19, Rubella, CMV and Herpes (TORCH) infections in the blood, BA type, surgical findings, and mortality were retrospectively analyzed.

\section{RESULTS}

Fifty-nine patients whose diagnose were confirmed by operative cholangiography had a surgical intervention for BA in our institution. Seven of these patients ( 3 girls and 4 boys with a median age of 60 days, (45-90 days) were classified as BASM. The major complaint of all patients was jaundice, with six patients exhibiting the symptoms since birth and the five with the disease onset at 20-days of age. The median total/direct blood bilirubin levels were 9.6(8.016.3) $\mathrm{mg} / \mathrm{dL} / 5.4$ (4.5-7.6) mg/dL. Median values from liver function test results alanine aminotransferase, aspartate aminotransferase and gamma-glutamyl transferase levels were 77 (53-147) IU/L, 201 (121503) IU/L, and 607 (247-780) IU/L, respectively. The levels of TORCH antibodies in blood were routinely evaluated by performing immunohistochemical analysis in all jaundiced patients. Five of the patients showed positive results for anti-CMV immunoglobulin M. All patients showed positive results for anti-CMV IgG and anti-toxoplasma IgG. All other serological tests revealed normal results.

One patient had type 2 BA and all others had type $3 \mathrm{BA}$.

Surgical findings were used for the diagnosis of BASM. Further analysis of these findings revealed that four of the seven patients had polysplenia, one had asplenia, (Figure 1). Five patients had preduodenal portal vein (Figure 2) and underwent duodenoduodenostomy. All patients had midgut malrotation and they had Ladd procedure. One patient had inferior vena cava interruption and one had a hepatic artery originating from the superior mesenteric artery. All patient data has been summarized in Table 1. The median time of follow-up was 4 years (1-5 years). All patients survived and 1 had a liver transplantation.

\section{DISCUSSION}

Twenty-five percent of BA cases are of the BASM subtype, which involves splenic malformations. Other anomalies are situs inversus, intestinal malrotation, preduodenal portal vein, interrupted vena cava, congenital portocaval shunts, cardiac anomalies, and central nervous system anomalies [14]. A major component of BASM is polysplenia. Not all patients have polysplenia or splenic malformation and the term "biliary atresia congenital structural anomalies" has been used instead but not widely accepted [7]. In this study, we found a BASM incidence rate of $11 \%$. Two of the patients in our study did not have any splenic malformation.

The cause of BA is not understood as well as BASM. $B A$ is destructive biliary fibrosis and the etiology is thought to be multifactorial (genetic, infection, toxin, immunological). The extrahepatic bile duct originates from the primordial bud of the intestine at 5 weeks gestation, followed by normal canalization at 6 weeks. BASM has some component which is definitely congenital such as midgut malrotation, asplenia, polysplenia, hepatic artery anomalies. Therefore, the etiology of BASM may be caused by defective organogenesis which is caused by 


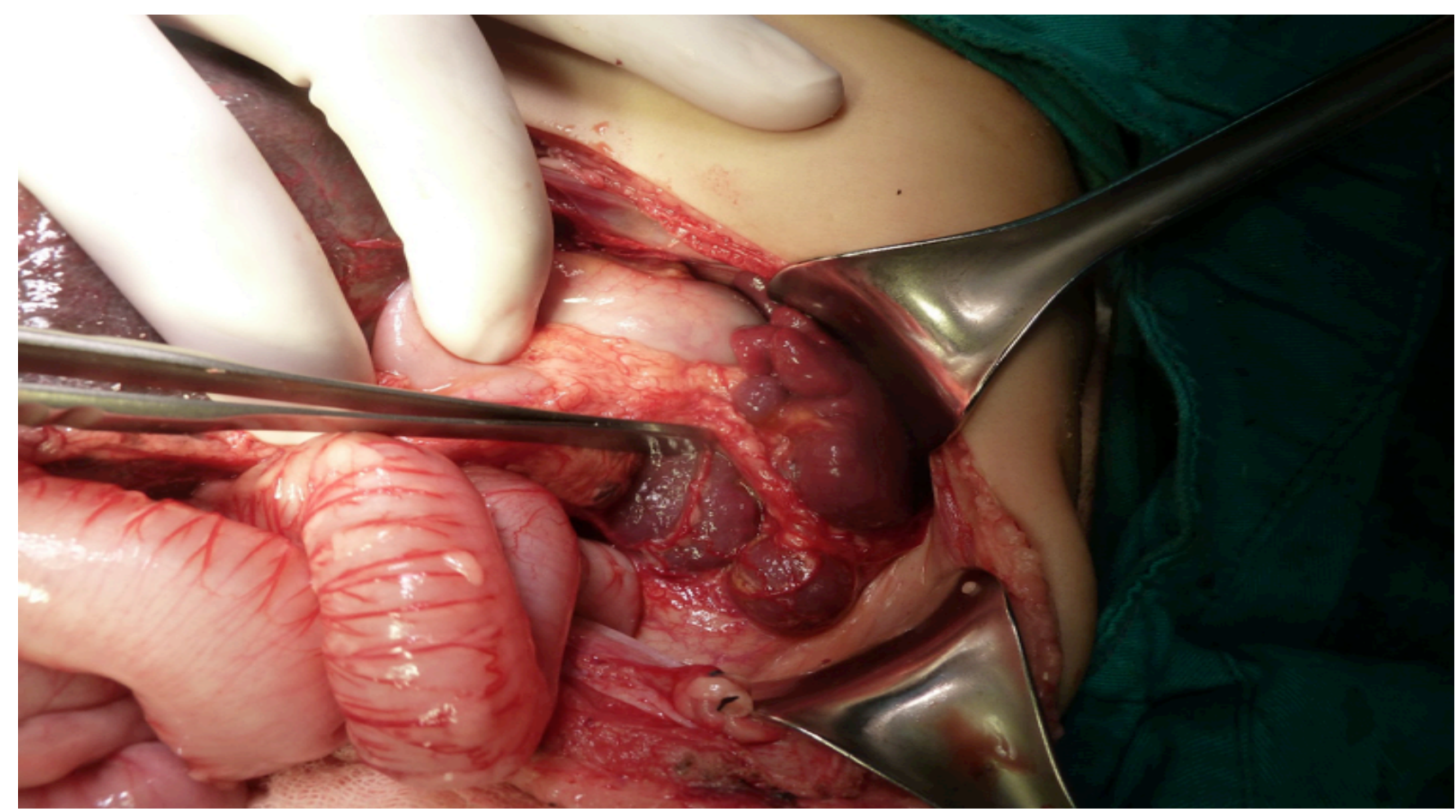

Figure 1. Polysplenia of patient 4.

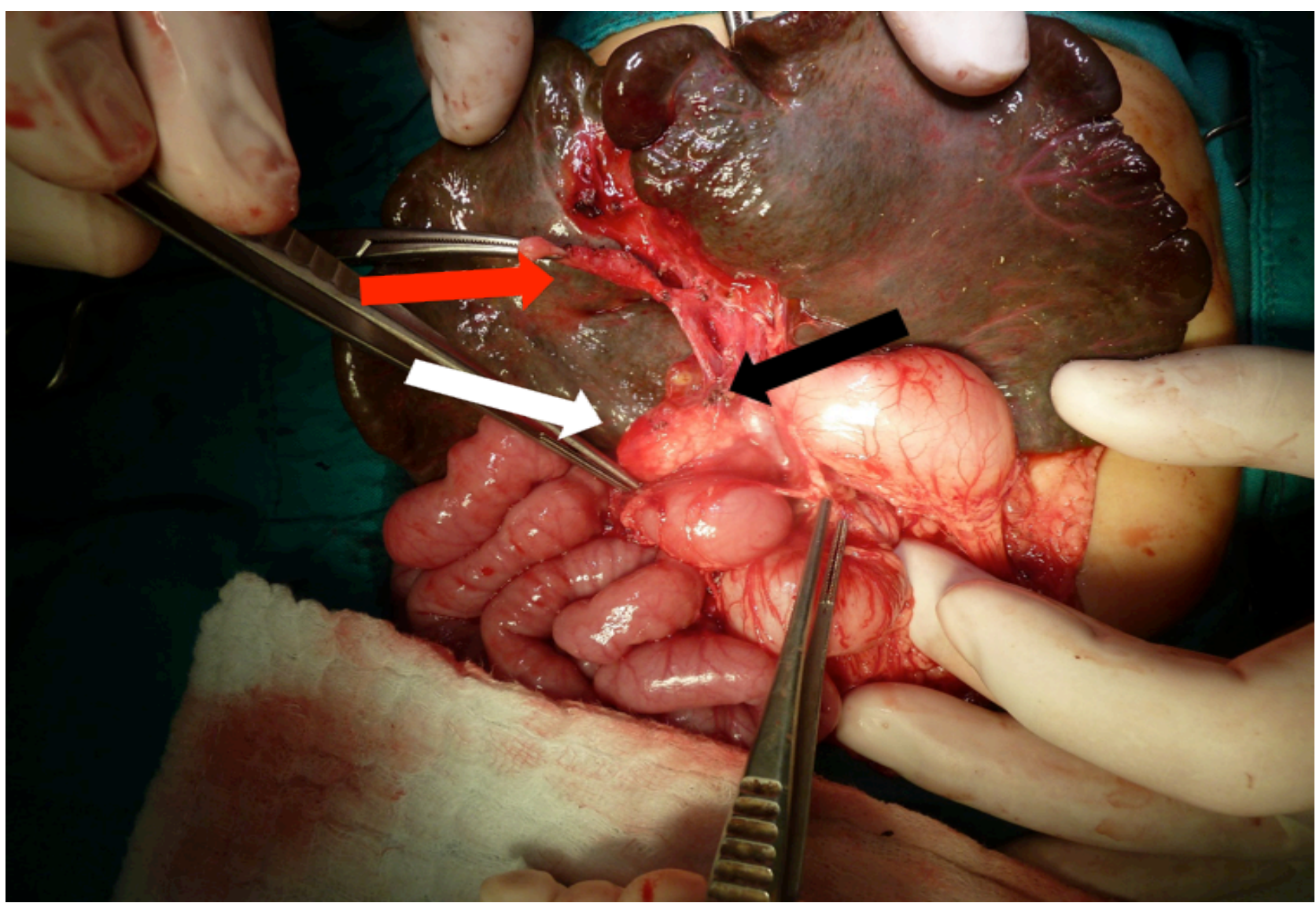

Figure 2. Preduodenal portal vein (black arrow), annular pancreas (white arrow) and atretic biliary ducts (red arrow) of patient 4. 
Table 1: Components of BAPS

\begin{tabular}{|c|c|c|c|c|c|c|c|c|}
\hline $\begin{array}{l}\text { Patients } \\
\text { No: }\end{array}$ & $\begin{array}{l}\text { Age (days), } \\
\text { sex }\end{array}$ & Polysplenia & $\begin{array}{l}\text { Preduodenal por- } \\
\text { tal vein }\end{array}$ & $\begin{array}{c}\text { Midgut } \\
\text { malrotation }\end{array}$ & \begin{tabular}{|c|} 
Hepatic \\
artery \\
anomalies
\end{tabular} & B.A. types & CMV Ig M & $\begin{array}{c}\mathrm{VCl} \\
\text { Anomaly }\end{array}$ \\
\hline 1 & $64, M$ & + & + & + & + & Type 3 & + & - \\
\hline 2 & $90, F$ & - & - & + & - & Type 2 & + & - \\
\hline 3 & $76, M$ & + & + & + & - & Type 3 & + & - \\
\hline 4 & $70, F$ & + & + & + & - & Type 3 & - & + \\
\hline 5 & $59, M$ & - & - & + & - & Type 3 & - & - \\
\hline 6 & $45, F$ & Asplenia & + & + & - & type 3 & + & - \\
\hline 7 & $50, M$ & + & + & + & - & Type 3 & + & - \\
\hline
\end{tabular}

genetic, infectious or immunological factors in the early fetal developmental period $[8,9]$.

In their case reports, Makin et al have discussed the etiology of BASM. Three patients had surgical intervention in early life because of other conditions (jejunal atresia and duodenal atresia). They observed BASM, but only took liver biopsies since enteral feeding was a higher priority and liver morphology was normal. Liver biopsies showed some non-diagnostic liver injury. Later on, they diagnosed and operated those patients due to BASM. This study suggests that bile duct injuries begin at birth in cases of BASM[10]

Lorent at all showed an association of cholangiocyte toxin called biliatresone with biliary atresia [11]. Biliatresone is first discovered in Australian livestock when investigating the cause of biliary atresia outbreak [12].

Regarding viral etiologic factors, the first report is published by Landing suggested in 1974 . He suggested viral factors may play the role of the pathogenesis of neonatal hepatitis, biliary atresia and choledochal cyst [13]. Reovirus, rotavirus, and CMV have been showed to play a role in the etiology of $B A[14,15]$. CMV is the most common viral cause of $B A$. Serological evidence of CMV infection has been observed in $20-40 \%$ of infants with BA in studies from Sweden, China and England[16-19]. CMV DNA was identified in $60 \%$ BA patients [20]. Therefore, association of CMV infection and BA is absolute but association of CMV infection and BASM is not well documented. When we searched the PubMed database using the keywords "biliary atresia splenic malformation, biliary atresia polysplenia syndrome cytomegalovirus" but did not find any relevant studies, even though there are several reports on BA and CMV infection. One of the important prospective studies concerning CMV IgM and BA was performed at King's College Hospital. The researchers evaluated and compared 20 CMV IgM-positive and $111 \mathrm{CMV}$ IgM-negative patients. One of the $20 \mathrm{CMV}$ IgM-positive and 17 of the $111 \mathrm{CMV}$ IgM-negative patients studied, had BASM. We recalculated the incidence of CMV infection among BAPS patients and found it to be 5\% [16]. Despite there were regional differences in the incidence of BA and BASM, the BASM incidence in the current study was similar to King's College Hospital. However, we found a higher rate of CMV infection with BASM at 71\% compared with the study from the King's College Hospital. CMV infection may also play an important role in BASM. However, our sample size was small. Further research concerning CMV infection in patients with BASM is recommended.

Preduodenal Portal Vein (PDPV):

The portal vein is usually formed by the confluence of the superior mesenteric and splenic veins and also receives blood from the inferior mesenteric, gastric, and cystic veins. The preduodenal portal vein passes the duodenum anteriorly and sometimes causes intestinal obstruction without BA [21]. The preduodenal portal vein is very rare and was first described by Knight in 1921[22]. The exact incidence is unknown since it may be asymptomatic. But PDPV is found 3 in 1000 biliary operations[23]. PDPV can be accompanied by other anomalies like situs inversus, biliary atresia, duodenal atresia or web, annular pancreas [24]. It is known that there are 3 types of clinical manifestation of PDPV; "complete duodenal 
obstruction, partial duodenal obstruction and asymptomatic." Choice of treatment is duodenoduodenostomy when a complete or partial duodenal obstruction is relevant. If it is asymptomatic, no operation may be performed and duodenoduodenostomy may be applied later when asymptomatic PDPV leads complete or partial duodenal obstruction. Some people with PDPV may survive without any symptoms related to PDPV [25]. However, we did prefer to perform duodenoduodenostomy even the patients did not have any symptom related to PDPV because it is known that asymptomatic PDPV may later progress into a symptomatic duodenal obstruction. Secondary surgeries to treat duodenal obstruction caused by PDPV in biliary atresia are dangerous by two reasons. One is surgical adhesion [26]. Second and our main reason to prefer duodenoduodenostomy is the secondary surgical area is very close to portoenterestomy site and secondary surgery may cause damage to this surgical site. Therefore, we prefer and recommend duodenoduodenostomy initially in order to avoid secondary surgery and the possibility of duodenal obstruction. Several reports claim that BASM has a worse prognosis than BA with a mortality rate of $74.1 \%$. However, the prognosis for BASM is no worse according to other reports $[8,9,27,28]$. Recent studies show that there is no difference in survival rates in BASM and BA [5]. The seven patients in our study have been followed for 5 years (1-5 years) uneventfully. One patient required liver transplantation.

\section{CONQUSIONS}

The association of BASM with other gastrointestinal anomalies and necessity of additional surgical procedures, such as the Ladd procedure and duodenoduodenostomy should be considered by the surgeon. Duodenoduodenostomy may be performed when there is a preduodenal portal vein even if the anomaly is asymptomatic.

Further research concerning CMV infection and BASM association is recommended.
[1] Nio M, Ohi R, Miyano T, et al. Five- and 10-year survival rates after surgery for biliary atresia: a report from the Japanese Biliary Atresia Registry. Journal of pediatric surgery 2003; 38(7): 997-00.

[2] Nio M, Wada M, Sasaki H, et al. Long-term outcomes of biliary atresia with splenic malformation. J Pediatr Surg 2015; 50(12): 2124-21.

[3] Zhan J, Feng J, Chen Y, et al. Incidence of biliary atresia associated congenital malformations: A retrospective multicenter study in China. Asian J Surg 2016.

[4] Davenport M, Tizzard SA, Underhill J, et al. The biliary atresia splenic malformation syndrome: a 28-year single-center retrospective study. J Pediatr 2006; 149(3): 393-00.

[5] Guttman OR, Roberts EA, Schreiber RA, et al. Biliary atresia with associated structural malformations in Canadian infants. Liver Int 2011; 31(10): 1485-93.

[6] Davenport M. Biliary atresia: clinical aspects. Semin Pediatr Surg 2012; 21(3): 175-84.

[7] Tanano H, Hasegawa T, Kawahara H, et al. Biliary atresia associated with congenital structural anomalies. J Pediatr Surg 1999; 34(11): 1687-90.

[8] Davenport M, Savage M, Mowat AP, et al. Biliary atresia splenic malformation syndrome: an etiologic and prognostic subgroup. Surgery 1993; 113(6): 662-68.

[9] Silveira TR, Salzano FM, Howard ER, et al. Congenital structural abnormalities in biliary atresia: evidence for etiopathogenic heterogeneity and therapeutic implications.
Acta Paediatr Scand 1991; 80(12): 1192-99.

[10] Makin E, Quaglia A, Kvist N, et al. Congenital biliary atresia: liver injury begins at birth. J Pediatr Surg 2009; 44(3): 630-33.

[11] Lorent K, Gong W, Koo KA, et al. Identification of a plant isoflavonoid that causes biliary atresia. Science translational medicine 2015; 7(286):286ra267.

[12] Waisbourd-Zinman O, Koh H, Tsai S, et al. The toxin biliatresone causes mouse extrahepatic cholangiocyte damage and fibrosis through decreased glutathione and SOX17. Hepatology 2016; 64(3): 880-93.

[13] Landing BH. Considerations of the pathogenesis of neonatal hepatitis, biliary atresia and choledochal cyst--the concept of infantile obstructive cholangiopathy. Prog Pediatr Surg 1974; 6:113-39.

[14] Tyler KL, Sokol RJ, Oberhaus SM, et al. Detection of reovirus RNA in hepatobiliary tissues from patients with extrahepatic biliary atresia and choledochal cysts. Hepatology 1998; 27(6): 1475-82.

[15] Riepenhoff-Talty M, Gouvea V, Evans MJ, et al. Detection of group $C$ rotavirus in infants with extrahepatic biliary atresia. J Infect Dis 1996; 174(1): 8-15.

[16] Zani A, Quaglia A, Hadzic N, et al. Cytomegalovirusassociated biliary atresia: An aetiological and prognostic subgroup. J Pediatr Surg 2015; 50(10): 1739-45.

[17] Fischler B, Ehrnst A, Forsgren $M$, et al. The viral association of neonatal cholestasis in Sweden: a possible link 
between cytomegalovirus infection and extrahepatic biliary atresia. J Pediatr Gastroenterol Nutr 1998; 27(1): 57-64.

[18] Fischler B, Svensson JF, Nemeth A. Early cytomegalovirus infection and the long-term outcome of biliary atresia. Acta Paediatr 2009; 98(10): 1600-02.

[19] Shen C, Zheng S, Wang W, et al. Relationship between prognosis of biliary atresia and infection of cytomegalovirus. World J Pediatr 2008; 4(2): 123-26.

[20] Xu Y, Yu J, Zhang R, et al. The perinatal infection of cytomegalovirus is an important etiology for biliary atresia in China. Clinical pediatrics 2012; 51(2): 109-13.

[21] Masumoto K, Teshiba R, Esumi G, et al. Duodenal stenosis resulting from a preduodenal portal vein and an operation for scoliosis. World J Gastroenterol 2009; 15(31): 3950-53.

[22] Knight HO. An Anomalous Portal Vein with Its Surgical Dangers. Annals of surgery 1921; 74(6): 697-99.

[23] Stevens JC, Morton D, McElwee R, et al. Preduodenal portal vein: Two cases with differing presentation. Archives of surgery 1978; 113(3): 311-13.

[24] Esscher T. Preduodenal portal vein--a cause of intestinal obstruction? Journal of pediatric surgery 1980; 15(5): 609-12.

[25] Yi SQ, Tanaka S, Tanaka A, et al. An extremely rare inversion of the preduodenal portal vein and common bile duct associated with multiple malformations. Report of an adult cadaver case with a brief review of the literature. Anatomy and embryology 2004; 208(2): 87-96.

[26] Miyake H, Fukumoto K, Yamoto M, et al. Surgical Management of Hiatal Hernia in Children with Asplenia Syndrome. European journal of pediatric surgery : official journal of Austrian Association of Pediatric Surgery [et al] = Zeitschrift fur Kinderchirurgie 2017; 27(3): 274-79.

[27] Vazquez J, Lopez Gutierrez JC, Gamez M, et al. Biliary atresia and the polysplenia syndrome: its impact on final outcome. J Pediatr Surg 1995; 30(3): 485-87.

[28] Karrer FM, Hall RJ, Lilly JR. Biliary atresia and the polysplenia syndrome. J Pediatr Surg 1991; 26(5): 524-27. 